\title{
Peter Wedderburn-Ogilvy
}

\section{Shortage of engineers}

Abstract. In this paper the word engineer applies equally to scientists. An "engineer” is, or should be, a person who has a degree in engineering. The title "engineer" should indicate that the holder is able to follow a train of thought on any subject within his or her field of expertise analytically, logically, honestly and objectively to its conclusion and ideally to be able, where appropriate, to initiate, organize and manage its conversion into reality. Engineering excludes "social engineering", the pernicious practice of making rules that are contrary to survival instincts. Invariably its results are the opposite to those expected, intended or advertised.

Nanotechnology Perceptions 13 (2017) 182-189

doi: 10.4024/N22WE17A.ntp.13.03 